\title{
Rapid molecular detection and isolation of canine distemper virus in naturally infected dogs
}

\author{
Hasbi Sait SALTIK ${ }^{1, \mathrm{a}, \bigotimes}$, Mehmet KALE ${ }^{1, \mathrm{~b}}$ \\ ${ }^{1}$ Burdur Mehmet Akif Ersoy University, Faculty of Veterinary Medicine, Department of Virology, Burdur, Türkiye \\ aORCID: 0000-0002-3283-7062, bORCID: 0000-0003-4156-1077
}

ARTICLE INFO

Article History

Received : 24.12.2020

Accepted: 08.11.2021

DOI: $10.33988 /$ auvfd. 846475

Keywords

Canine

Cell culture

Distemper

Fluorescent antibody

TaqMan

$\bowtie$ Corresponding author

hasbi.saltik@gmail.com

How to cite this article: Saltık HS, Kale M (2023):

Rapid molecular detection and isolation of canine distemper virus in naturally infected dogs. Ankara Univ Vet Fak Derg, 70 (1), 49-56. DOI: 10.33988/auvfd.846475.

\begin{abstract}
A B STRACT
The canine distemper virus (CDV), which infects dogs and a broad range of animal species, remains a serious concern in Türkiye and across the world. The current study shows that CDV can be detected and isolated rapidly and specifically in naturally infected dogs. Whole blood, nasal swab, ocular swab, rectal swab, and urine samples from 50 stray dogs were used in the study $(n=$ 250). The presence of the CDV genome was confirmed in 105 (42\%) samples using one-Step real-time RT-PCR. In total, 39 dogs were diagnosed with CDV infection based on the detection of cytopathic effects in MDCK, which was verified by the fluorescent antibody technique. A total of 12 one-Step realtime RT-PCR negative samples, consisting of 4 rectal swabs and 8 urine samples, were found to be positive by virus isolation. Blood, nasal swab, ocular swab $(P<0.01, r=1)$, rectal swab $(P<0.01, r=0.844)$, and urine samples $(P<0.01$, $r=0.697)$ all showed positive correlations in the tests for viral genome detection and virus isolation. CPE levels of high 37 (31.62\%), medium 26 $(22.23 \%)$ and low 54 (46.15\%) were detected in a total of $117(46.8 \%)$ samples with viral growth in cell culture. The highest CPE levels detected by FAT were for rectal swab and urine samples. In conclusion, the one-step real-time RTPCR method on rectal swab samples proved to be a very sensitive method for the rapid and reliable CDV detection. Besides, non-modified MDCK can be used to isolate CDV from naturally infected dogs.
\end{abstract}

\section{Introduction}

The canine distemper virus (CDV) causes an extremely contagious and fatal infection in domestic dogs and some other carnivores $(3,4,33,37)$. CDV belongs to the Morbillivirus genus of the Paramyxoviridae family of viruses. Morbilliviruses are negative-sense singlestranded RNA viruses with genomes approximately $16 \mathrm{~kb}$ in size. Although they are known to infect a large variety of susceptible wild species, the main reservoir for CDV has largely been dogs $(21,39)$. The virus is a continuous threat to dogs, especially young dogs with inadequate immunity $(7,11,20,49)$. Some studies have shown that unvaccinated and stray carnivorous species can contract a $\mathrm{CDV}$ infection and threaten the vaccinated population of $\operatorname{dogs}(8,11,15)$. The prevalence of CDV is higher in urban and rural areas where there is no practice in place for regular vaccinations and where a higher number of stray dogs exist $(13,18,42)$. Regular vaccination has proven to help reduce the incidence of disease in domestic dogs (12, 24, 30).

CDV infections can cause multi-systemic symptoms, involving the respiratory, gastrointestinal, and central nervous systems $(6,32)$. The most common clinical symptoms are fever, cough, oculo-nasal discharge, diarrhea, lymphopenia, skin hyperplasia, and tremors (27, 43). The disease is primarily transmitted through aerosols or respiratory droplets since the infectious viral particles are abundant in the respiratory tract of infected dogs $(1$, 21). Since there may also be viral scattering with secretions of clinical and subclinical sick animals, contact transmission becomes another important transmission route.

The high mortality rates of CDV infections make it necessary to speed up the diagnostic procedure so that the infected dogs can be effectively quarantined and treated promptly. Hence there is a need for a sensitive and rapid 
method to detect even small amounts of virus present in the early infection stages (17). Serological methods are useful in cases of CDV infection only when the results are evaluated together with clinical symptoms (42). However, it is difficult to follow the clinical symptoms in stray dogs. Moreover, subclinical cases often complicate the situation. A definitive diagnosis of CDV infection by virus isolation is fastidious as well as time-consuming. Therefore, researchers have developed modified cell cultures that are highly sensitive for characteristic CPEs of CDV when applied to clinical samples (44). Unfortunately, it is difficult to access such modified cells for routine diagnostic procedures. This study aimed to explore a rapid diagnostic method involving molecular and cell culture techniques to detect CDV in clinical samples of naturally infected dogs. Such an efficient and cost-effective method can make the control of CDV infection much easier. Our results also showed that CDV field strains could be replicated in non-modified MDCK without adaptation.

\section{Materials and Methods}

Samples: The samples for this study were collected from unvaccinated stray dogs under 1 year of age with clinical symptoms compatible with CDV from the Western Mediterranean Region of Türkiye during 2016-17. A total of 250 samples were obtained from $50 \mathrm{dogs}$ and stored at $-80^{\circ} \mathrm{C}$ (Haier, China). These included whole blood (BS), nasal swab (NaS), ocular swab (OcS), rectal swab (ReS), and urine (UrS) samples (50 each). The swab samples were processed by homogenization $(10 \% \mathrm{w} / \mathrm{v})$ in phosphate-buffered saline (PBS) supplemented with $1 \%$ antibiotic-antimycotic agents. The homogenates and urine samples were centrifuged at $2000 \mathrm{xg}$ for $10 \mathrm{~min}$ at $4^{\circ} \mathrm{C}$. Then $250 \mu \mathrm{L}$ of the supernatants were collected for molecular testing. The remaining parts were stored at $80^{\circ} \mathrm{C}$ for virus isolation. All samples were quickly thawed in a $37^{\circ} \mathrm{C}$ water bath and passed through Millipore filters (Sartorius, Germany) of $0.22 \mu \mathrm{m}$ pore size before inoculation. Blood samples were collected into EDTAtreated tubes and centrifuged at $4{ }^{\circ} \mathrm{C}$ and $1500 \mathrm{xg}$ for 10 min until a buffy coat got separated. This buffy coat was diluted with $1 \mathrm{~mL}$ PBS after washing. The samples were divided into 4 groups according to the age of dogs as follows: $0-3,4-6,7-9$, and $10-12$ months of age. This study was approved by the Animal Ethics Committee (AEC) Burdur Mehmet Akif Ersoy University, Türkiye (No: 28-174-2016). The following assays were applied for all samples.

Molecular Detection: Viral RNA was extracted from 250 $\mu \mathrm{L}$ of supernatant, using a commercial kit $\left(\operatorname{RiboEx}^{\mathrm{TM}}\right.$, GeneAll $^{\circledR}$, Korea) according to the manufacturer's instructions. One-step real-time RT-PCR assay was performed on a StepOne ${ }^{\mathrm{TM}}$ (48-well) instrument (Applied Biosystems $^{\mathrm{TM}}$, USA), using TaqMan probes and the onestep real-time RT-PCR kit (GeneAll ${ }^{\circledR} 2 \mathrm{xHyperScript}^{\mathrm{TM}}$, Korea). Primer sets and probes targeting the $\mathrm{N}$ proteinencoding gene and cycling conditions used were the same as those previously described by Elia et al. (17), with only slight modifications (Table 1). The reactions were performed according to the manufacturer's instructions. Positive and negative control reactions were included for each reaction. Nuclease-free water and CDV RNA (strain Onderstepoort) were used as the negative and positive control, respectively. The protocol for the RT step involved incubation for $5 \mathrm{~min}$ at $58^{\circ} \mathrm{C}$ and $50^{\circ} \mathrm{C}$. The cycling conditions included a pre-denaturation for $30 \mathrm{~s}$ at $95^{\circ} \mathrm{C}$, followed by 50 cycles each of $95^{\circ} \mathrm{C}$ for $5 \mathrm{~s}, 60^{\circ} \mathrm{C}$ for $30 \mathrm{~s}$, and $72^{\circ} \mathrm{C}$ for $1 \mathrm{~s}$. After the final cycle, the tubes were incubated for an additional $30 \mathrm{~s}$ at $40^{\circ} \mathrm{C}$.

Cell culture and virus isolation: For the virus isolation, $400 \mu \mathrm{l}$ of supernatants were transferred to 24 -well plates with a confluent monolayer of MDCK cells. A well containing only cells but no virus or serum was used as the control for each 24-well plate. The plates were then incubated at $37^{\circ} \mathrm{C}$ for $1 \mathrm{~h}$. After the adsorption step, $2 \mathrm{~mL}$ of Dulbecco's modified Eagle medium (DMEM) and high glucose (4.5 g/L) supplemented with L-Glutamine (Capricorn, Germany) were added along with antibiotics (10\%) and antimycotics (7\%). The plates were then incubated at $37^{\circ} \mathrm{C}$ and $5 \% \mathrm{CO} 2$ for six days. After two serial passages, the plates were examined using a cell culture microscope (Life Technologies ${ }^{\mathrm{TM}}$ Floid ${ }^{\circledR}$ Cell Imaging Station, USA) for the presence of cytopathic effects (CPE). All supernatants gathered from the last passage were used for the Fluorescent Antibody Test (FAT).

Table 1. Primer pairs and probe set for the amplification of CDV $N$ gene.

\begin{tabular}{lllc}
\hline Primer/Prob* & Position & Sequence (5'-3') & Size (bp) \\
\hline CDV-F & $905-931$ & AGCTAGTTTCATCTTAACTATCAAATT & 87 \\
CDV-R & $966-987$ & TTAACTCTCCAGAAAACTCATGC & \\
CDV-Pb & $934-963$ & FAM-ACCCAAGAGCCGGATACATAGTTTCAATGC-TAMRA** & \\
\hline
\end{tabular}

**6-carboxyfluorescein (FAM), 6-carboxytetramethylrhodamine (TAMRA). 
Fluorescent Antibody Test: $250 \mu \mathrm{L}$ of each supernatant was transferred to 6-well plates containing coverslip and seeded with MDCK cells. The control used for each 6-well plate was a well with cells only. The plates were incubated at $37^{\circ} \mathrm{C}$ for $1 \mathrm{~h}$. After the adsorption step, $4 \mathrm{~mL}$ DMEM (with high glucose L-Glutamine) was added along with antibiotics (10\%) and antimycotics (7\%). All plates were incubated at $37^{\circ} \mathrm{C}$ and $5 \% \mathrm{CO}_{2}$ for five days, after which the plate coverslips were studied for FAT. The coverslips were rinsed in PBS. The staining procedure followed involved commercially available CDV polyclonal antiserum conjugated to fluorescein isothiocyanate (FITC) (catalog no: CJ-F-CDV-10ML; VMRD, USA) for direct FAT. The results were evaluated in a Floid ${ }^{\circledR}$ Cell Imaging system. The CDV-FAT substrate slide (containing two wells: one positive and one negative, catalog no: SLDFAC-CDV; VMRD, USA) was used as a reference. The coverslips were examined for the presence of CDV antigen-positivity using a cell culture microscope Floid ${ }^{\circledR}$ Cell Imaging system. The positivity was calculated based on a previously described method, as the number of CDV antigen-positive cells divided by the total cells (25). CPEs were identified for each sample, at different levels (high, medium, and low) using FAT.

Statistical analysis: Data were analyzed using the IBM SPSS $^{\circledR}$ Statistics 23.0 software. The statistical evaluation was performed using the Chi-squared and Spearman's correlation tests.

\section{Results}

One-Step real-time RT-PCR: 31 out of all the $50 \mathrm{dogs}$ tested positive for CDV infection. The 87-bp fragment was amplified from extracts, and it was used to identify the virus by targeting the $\mathrm{N}$ protein. Specific signal amplification was obtained for the positive samples with cycle threshold $(\mathrm{Ct})$ values ranging from 18 to 36 . In total,
$105(42 \%)$ samples were positive for the presence of the CDV genome. BS, NaS, OcS, ReS, and UrS were positive in 20 (40\%), 23 (46\%), 22 (44\%), 27 (54\%) and 13 (26\%) samples, respectively (Table 2 ).

Cell culture and virus isolation: In total, 39 out of $50 \mathrm{dogs}$ were found to be positive by virus isolation. In MDCK cells, the presence of CPE was detected in a total of 117 (46.8\%) samples, their distribution based on sample type being the following: 20 (40\%) BS, 23 (46\%) NaS, 22 (44\%) OcS, 31 (62\%) ReS, and 21 (42\%) UrS (Figure 1 and Table 2). A total of 12 one-Step real-time RT-PCR negative samples were positive by virus isolation, of which 4 were ReS, and 8 were UrS.

Fluorescent Antibody Test: A strong bright green fluorescence was detected in the cytoplasm of the infected cells, whereas no green fluorescence was observed in the control coverslips. Characteristic inclusion bodies of CDV were also counted as antigen positivity. However, nonspecific yellow stainings were not included in the interpretation. The interpretation of results was based on the intensity of fluorescence/staining reaction and accordingly categorized as high $(>60 \%)$, middle (30$60 \%$ ), and low $(<30 \%$ ) levels of CPE (Figure 2). CPE levels for the different sample types are shown in Table 3.

Statistical analysis: In viral genome detection, the relationship between real-time RT-PCR and virus isolation, demonstrated positive correlations for $\mathrm{BS}, \mathrm{NaS}$, and $\operatorname{OcS}(\mathrm{P}<0.01, \mathrm{r}=1), \operatorname{ReS}(\mathrm{P}<0.01, \mathrm{r}=0.844)$, and UrS $(\mathrm{P}<0.01, \mathrm{r}=0.697)$. The highest positivity rate was detected in the age group of $0-3$ months $(68.1 \%)$ for viral genome detection and in the age group of 4-6 months (90.9\%) for virus isolation. The distribution of CDV isolation and genome positivity rates in different age groups are shown in Table 4.

Table 2. Comparison of the results of real-time RT-PCR and virus isolation.

\begin{tabular}{ccccccc}
\hline Real-time & CPE in & \multicolumn{3}{c}{ Sample numbers* } \\
\cline { 2 - 6 } RT-PCR & MDCK & BS & NaS & OcS & ReS & UrS \\
\hline+ & + & $20(40 \%)$ & $23(46 \%)$ & $22(44 \%)$ & $27(54 \%)$ & $13(26 \%)$ \\
- & + & 0 & 0 & 0 & $4(8 \%)$ & $8(16 \%)$ \\
+ & - & 0 & 0 & 0 & 0 & 0 \\
- & - & $30(60 \%)$ & $27(54 \%)$ & $28(56 \%)$ & $19(38 \%)$ & $29(58 \%)$ \\
\hline
\end{tabular}

*BS: Blood, NaS: Nasal swab, OcS: Ocular swab, ReS: Rectal swab, UrS: Urine.

Table 3. Cytopathic effect (CPE) results according to the samples.

\begin{tabular}{ccccc}
\hline & High & Levels of CPE & Low & Total \\
\hline Samples* & 1 & Middle & 17 & $20(17.1 \%)$ \\
BS & 1 & 2 & 12 & $23(19.6 \%)$ \\
NaS & 3 & 10 & 14 & $22(18.8 \%)$ \\
OcS & 21 & 5 & 4 & $31(26.5 \%)$ \\
ReS & 11 & 3 & 7 & $21(17.9 \%)$ \\
UrS & $37(31.62 \%)$ & $26(22.23 \%)$ & $54(46.15 \%)$ & $117(\% 100)$ \\
Total & &
\end{tabular}

*BS: Blood, NaS: Nasal swab, OcS: Ocular swab, ReS: Rectal swab, UrS: Urine. 


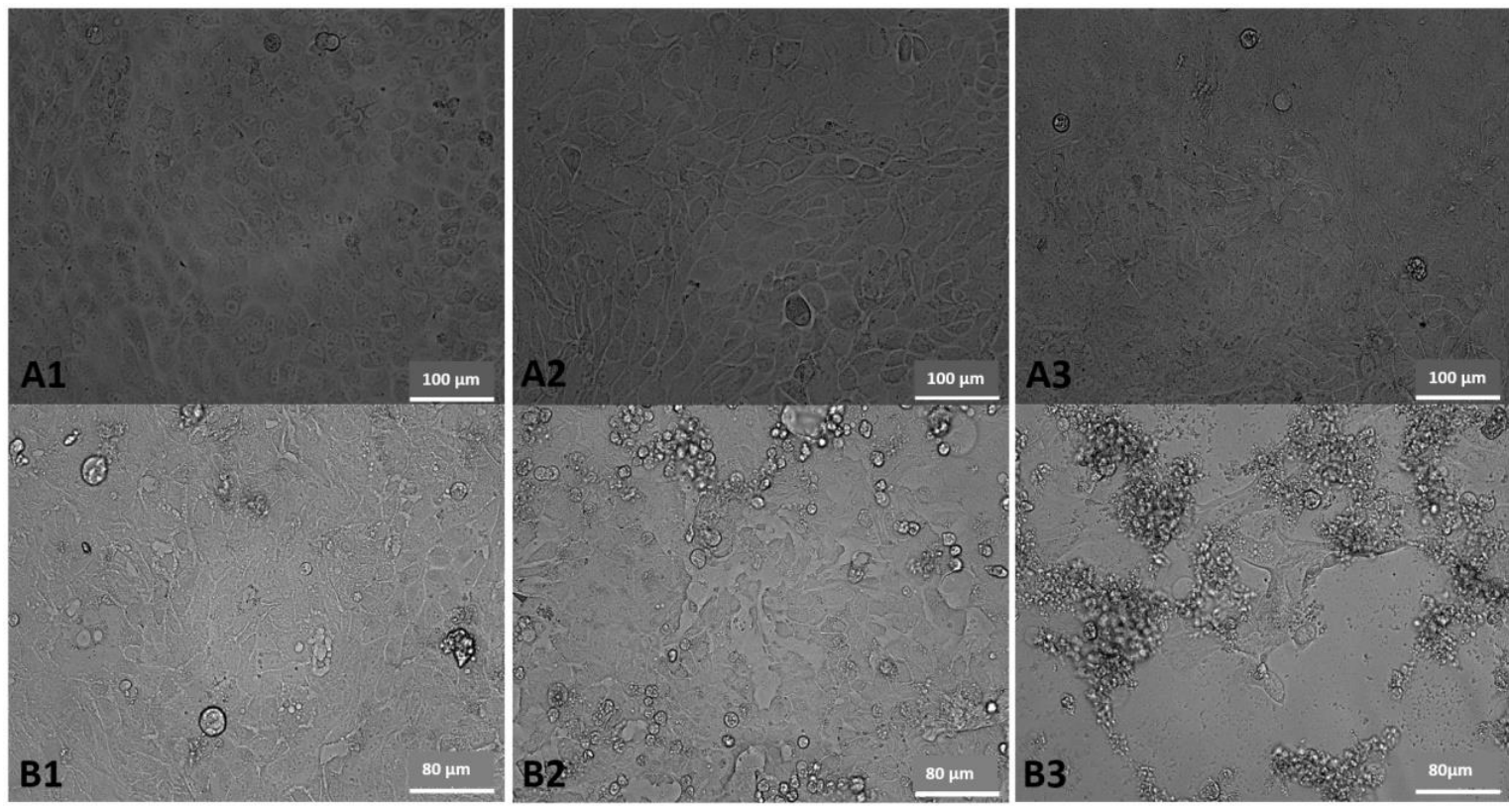

Figure 1. Cytopathic effect (CPE) of CDV in MDCK cells infected with rectal swab samples belongings to dog no 24.

A1-3: Untreated control cells. A1: 48h, A2: 96h, A3: 144h later. B1-B3: Sample inoculated cells. B1: 48h, B2: 96h, B3: 144h later. Pictures were taken with a Sony 1.3MP 1/3" ICX445 EXview HAD CCD camera, 20x objective with 460x optical magnification under an inverted microscope (Life Technologies ${ }^{\mathrm{TM}}$ Floid ${ }^{\circledR}$ Cell Imaging Station, USA).
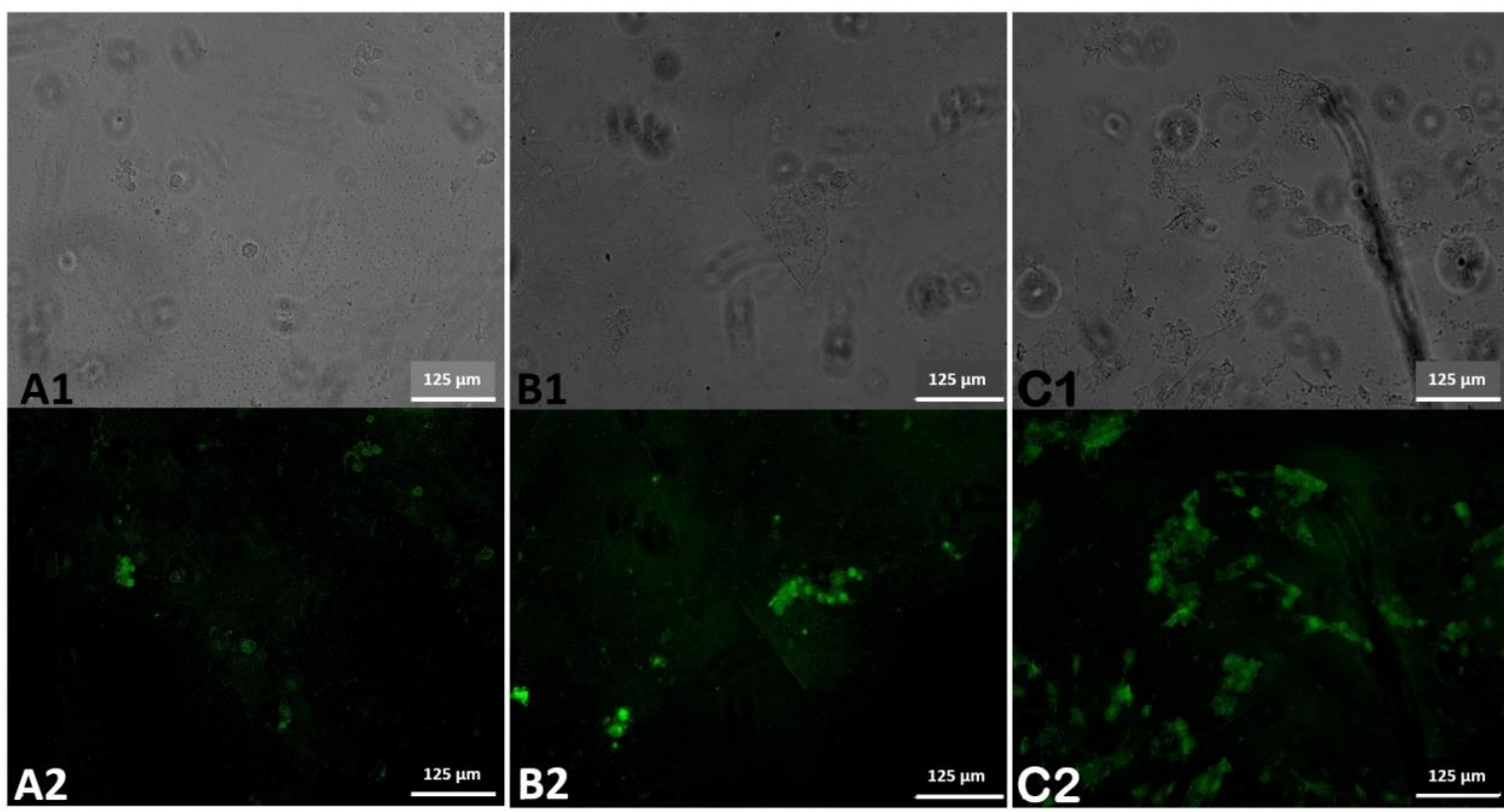

Figure 2. CPE of MDCK cells before FAT.

(A1: dog no 40, urine-low; B1: dog no 37, ocular swab-medium; C1: dog no 10, rectal swab-high). FAT was done on CDV-infected MDCK cells at 6 days post-inoculation (A2, B2, C2).

(A typical apple-green fluorescence indicating positive CDV antigens in infected cells).

Table 4. Distribution of viral genome and virus isolation results by age groups. Real-time RT-PCR and virus isolation-FAT results according to age.

\begin{tabular}{|c|c|c|c|c|c|}
\hline \multirow{2}{*}{$\begin{array}{l}\text { Age group } \\
\text { Months }\end{array}$} & \multicolumn{2}{|c|}{ Real-time RT-PCR } & \multicolumn{2}{|c|}{ CPE } & \multirow{2}{*}{ Total } \\
\hline & $(+)$ & $(-)$ & $(+)$ & $(-)$ & \\
\hline $0-3$ & $15(68.1 \%)$ & 7 & $17(77.2 \%)$ & 5 & 22 \\
\hline $4-6$ & $6(54.5 \%)$ & 5 & $10(90.9 \%)$ & 1 & 11 \\
\hline $7-9$ & $6(66.6 \%)$ & 3 & $6(66.6 \%)$ & 3 & 9 \\
\hline $10-12$ & $4(50 \%)$ & 4 & $6(75 \%)$ & 2 & 8 \\
\hline Total & $31(62 \%)$ & 19 & $39(78 \%)$ & 11 & 50 \\
\hline
\end{tabular}




\section{Discussion and Conclusion}

CDV infection causes high morbidity and mortality in domestic and wild canids across the world (35). The progress of the disease can differ from strain to strain and also depends on the amount of virus as well as the age, immunity level, and environmental factors of the sensitive host (32). The disease is easily transmitted to young and unvaccinated dogs, which come into direct or indirect contact with infected dogs (2). Dogs that have not received the necessary antibodies through either colostrum or vaccination during the first 12 months of their life are more susceptible to infection $(16,21,23)$. Several molecular assays are widely used to detect CDV infections. It has been reported that CDV infection has a higher chance of detection using the RT-PCR method as compared to immunohistochemistry methods, especially in cases of subacute and chronically infected dogs (26, 41). Some studies conducted using the conventional PCR techniques in Türkiye have reported the presence of CDV genomes in various samples collected from dogs $(36,40)$. In cases where intercalating dyes were used to measure real-time PCR products, there is the disadvantage of detecting the sum of all specific and non-specific PCR products (5). Recently, the real-time RT-PCR technique based on the TaqMan Probe system has enabled rapid, accurate, and highly specific diagnosis of CDV (16). The TaqMan Probe is used to avoid the disadvantages met while using other probes in detecting both specific and non-specific PCR amplification. The real-time RT-PCR method is preferred due to its higher sensitivity and specificity as compared to other diagnostic methods (14, 17). Diagnosis of CDV is especially challenging due to the diverse and non-specific clinical manifestations and due to the high seroprevalence rate in sub-clinical dogs. Veterinarians are routinely confronted with cases where the clinical picture is compatible with the disease, but the diagnostic tests yield contradictory results. This study is unique in being the first in the detection of the CDV genome in Türkiye using the one-Step TaqMan real-time RT-PCR assay.

The advantages of the one-Step TaqMan real-time RT-PCR method have been reported in several previous studies as well $(5,14,16,17,45)$. The highly conserved nucleocapsid gene region of CDV was targeted in this study (17). This study aimed to obtain more specific and reliable positive results using fluorogenic probes that identify only specific PCR products. Based on our results (Table 2), we can confidently state that fluorogenic probes are highly useful reagents for the detection of CDV in naturally infected dogs. The detection was performed in a sensitive, specific, rapid, and reliable manner using the specific primer/probes designed for the reaction. Realtime RT-PCR yielded a high rate of positivity for CDV infection in the 0-3 months of age category, as indicated in Table 4.

As a result, we have successfully shown that a rapid and reliable diagnosis can be made for CDV infection in very young dogs using the real-time system with the TaqMan probe. Disadvantages of PCR methods in viral genome detection have already been widely reported (19, $34,38)$. Some of these disadvantages are that the viral load may be too low in samples taken from naturally infected animals and that even smaller volumes of these samples are used in the PCR test. Moreover, the fragile nature of the RNA genome and the contamination with RNases from the environment may adversely affect the results of a PCR test. As a result, the potential negative effects of PCR inhibitors hamper viral genome detection. These disadvantages may lead to false-negative results. In our study, virus isolation and FAT techniques were used to eliminate these disadvantages particularly. Moreover, it is always important to confirm test results with other reliable methods to eliminate the false-negative results.

CDV polyclonal antiserum is known to be highly suitable for specific detection of CDV infection in cell cultures, as it does not stain for other non-specific viral agents. It is thus a specific tool used for the diagnosis of acute and primary infections in dogs and will continue to be the most popular critical reagent used in routine diagnosis via FAT. The only limitation of FAT is that it requires fluorescent imaging microscopy and the presence of skilled lab staff. Despite limitations, the FAT is one of the best methods of diagnosis as it is rapid, flexible, and accurate (31).

Viral growth has been reported to successfully occur in MDCK cells and Vero but not in MV1 cells. Based on this study, wild-type CDV isolation in MDCK cells proved to be the most effective, though CPEs are the most evident in Vero (28). In our study, the characteristic CPEs observed in the MDCK cells were also identified by the CDV-specific antiserum. Similar findings have also been reported in other studies that were based on the isolation of the CDV in non-modified MDCK cells without adaptation $(46,47)$. It was reported that the Veroexpressing signaling lymphocyte activation molecule (SLAM) was highly useful for the isolation of CDV from clinical samples. The major advantage of this cell type for $\mathrm{CDV}$ isolation is that $\mathrm{CDV}$ propagation can be detected as early as 1-day post-infection (44). In our study, the notable CPEs could be observed in MDCK cells 6-days postinoculation.

Our findings show that some CDV strains can infect MDCK cells without the need for adaptation. The viral load in samples from naturally infected animals could be quite low and, the isolation of CDV in cell cultures tends to be prolonged, requiring blind-passages before the occurrence of CPEs (28). Blind passages play a crucial 
role in virus isolation in natural infections. Therefore, at least two blind passages were made in the cell cultures of high-volume cultivated samples.

In our study, ReS, and UrS were the most prominent samples with a high level of CPE identification (Table 3). The lowest level of CPEs was in the BS. A study by Pawar et al. (37) supports these findings of our study. CDV can be detected at high titers from several body fluids, including urine $(17,41)$. High levels of CPE were detected in $\mathrm{ReS}$ and UrS, which may be due to the high reproducibility of viral load in these samples (17). Here we report the first isolation of CDV in MDCK cell culture from naturally infected dogs in Türkiye and the successful isolation from urine samples. Likely, our careful sampling at the right time in the post-infection period increased the efficiency of CDV isolation. According to the findings of this study, notable CPEs were observed in infected MDCK cells, and the optimal harvest time was 6 days after inoculation, with UrS reaching the highest CPE level. Although there are previous studies related to $\mathrm{CDV}$ isolation from different sample types, they provide limited information about isolation from urine samples in particular $(44,47)$. In the CDV infection, the sample type used for molecular diagnosis and virus isolation may depend on the clinical symptoms (36). Based on our data, we recommend the use of ReS for CDV diagnosis and isolation. The data we obtained are coherent with several previous studies $(17,22,40)$.

The highest amount of positivity was found to be in the $0-3$ months age group for viral genome determination and in the 4-6-months age group for virus isolation (Table $4)$. According to these results, it was concluded that dogs under 6 months of age were at higher risk of CDV infection. The results of Gray et al. (20) support our findings. In stray dogs using the same habitats as infected animals, such high rates of CDV infection would likely be caused by continuous exposure to secretions/excretions of infected animals. Moreover, these dogs are periodically collected and kept in shelters for ear tagging, spaying, vaccination, etc. The potential for exposure and CDV transmission to susceptible dogs only increases during this period. Additionally, the fact that CDV persists in infected animals (21) and that they can spread the virus again after immunosuppression is a permanent threat to susceptible animal species. However, CDV prevalence was reported to be lower in places where vaccination programs are applied regularly $(10,30,48)$. Mostly, domestic dogs that are taken out twice a day should be prevented from interacting with stray dogs. However, it may be difficult to prevent the dogs from exposure to infected materials in the area that is contaminated with secretion and excretion of infected dogs. Such material threatens the vaccinated dogs as well (9). Since there is no vaccination program intended for stray dogs, all carnivores are at risk of contracting the disease (29).

It is important to have a vaccination program for stray dogs to decrease the constant presence of the virus in the environment in general. It has been shown in our study that field strains can be isolated by methods that are not difficult to apply in practice. In this way, using field strains in the vaccines will result in a more effective campaign against CDV. Stray dogs that roam for food, water, shelter, mating, etc., are the key reservoirs that allow the virus to circulate and persist in rural and urban areas. Moreover, it is necessary to follow wildlife animal movements as well. Since there is no control program in place for CDV in the wildlife, it increases the risk of transmission between wild and domestic carnivores. The one-step real-time RT-PCR and virus isolation methods used in this study are the preferred methods for the detection of CDV in clinical samples. These methods are sensitive, provide highly specific results, and are useful for rapid detection in naturally infected dogs. Besides, according to the findings of this study, non-modified MDCK cells should be preferred for the isolation of CDV from naturally infected dogs. CDV is likely to remain an important threat to dogs, particularly those that are $0-6$ months of age, if there is no program in place to control the increasing population of stray dogs in urban areas (42).

We concluded that ocular swabs and blood samples are the preferred alternative samples, although rectal and nasal swabs were found to be the best clinical samples for the detection of CDV. Based on our findings in the urine samples, we can also suggest that there is a need for more detailed studies on urinary system symptoms in infected dogs.

\section{Acknowledgement}

This article was summarized from the $\mathrm{PhD}$ thesis by Hasbi Sait SALTIK (Burdur Mehmet Akif Ersoy University, Institute of Health Sciences).

\section{Financial Support}

Financial support of this study by the University of Burdur Mehmet Akif Ersoy BAP grant number 0403-DR-16 is highly appreciated.

\section{Conflict of Interest}

The authors declared that there is no conflict of interest.

\section{Author Contributions}

HSS conceived and planned the experiments. HSS carried out the experiments. HSS planned and carried out the simulations. HSS contributed to sample preparation. HSS and MK contributed to the interpretation of the results. HSS took the lead in writing the manuscript. All authors 
provided critical feedback and helped shape the research, analysis and manuscript.

\section{Data Availability Statement}

The data supporting this study's findings are available from the corresponding author upon reasonable request.

\section{Ethical Statement}

This experiment was approved and performed under the guidelines of the Animal Ethics Committee (AEC) Burdur Mehmet Akif Ersoy University, Türkiye (No:28-1742016).

\section{Animal Welfare}

The authors confirm that they have adhered to ARRIVE Guidelines to protect animals used for scientific purposes.

\section{References}

1. Anderson DE, Wang LF (2011): New and emerging paramyxoviruses. 435-459. In: SK Samal (Ed), The Biology of Paramyxoviruses. Caister Academic Press, Maryland, USA

2. Appel MJ, Gillespie JH (1972): Canine distemper virus. 196. In: SGC Hallauer and K Meyer (Ed), Virology Monographs. Springer, Vienna.

3. Appel MJG, Summers B (1999): Canine distemper: current status. 68-72. In: L Carmichael (Ed), Recent Advances in Canine Infectious Diseases. International Veterinary Information Service (IVIS).

4. Appel MJG, Summers BA (1995): Pathogenicity of morbilliviruses for terrestrial carnivores. Vet Microbiol, 44, 187-191.

5. Arya M, Shergill IS, Williamson M, et al (2005): Basic principles of real-time quantitative PCR. Expert Rev Mol Diagn, 5, 209-219.

6. Beineke A, Puff C, Seehusen F, et al (2009): Pathogenesis and immunopathology of systemic and nervous canine distemper. Vet Immunol Immunopathol, 127, 1-18.

7. Blancou J (2004): Dog distemper: imported into Europe from South America. Hist Med Vet, 29, 35-41.

8. Blixenkrone-Moeller $M$, Svansson $\mathbf{V}$, Have $\mathbf{P}$, et al (1993): Studies on manifestations of canine distemper virus infection in an urban dog population. Vet Microbiol, 37, 163-173.

9. Calderon MG, Remorini P, Periolo O, et al (2007): Detection by RT-PCR and genetic characterization of canine distemper virus from vaccinated and non-vaccinated dogs in Argentina. Vet Microbiol, 125, 341-349.

10. Chappuis G (1995): Control of canine distemper. Vet Microbiol, 44, 351-358.

11. Demeter Z, Palade EA, Rusvai M (2009): Canine distemper: Still a major concern in Central Europe. Lucr Stiint Univ Stiint Agric Banat Timis Med Vet, 42, 136-150.

12. Di Sabatino D, Savini G, Lorusso A (2015): Canine distemper and endangered wildlife: Is it time for mandatory vaccination of dogs. Vaccine, 33, 6519.
13. Diaz NM, Mendez GS, Grijalva CJ, et al (2016): Dog overpopulation and burden of exposure to canine distemper virus and other pathogens on Santa Cruz Island, Galapagos. Prev Vet Med, 123, 128-137.

14. Dorak MT (2007): Real-time PCR. Taylor \& Francis. New York.

15. Ek-Kommonen C, Sihvonen L, Pekkanen K, et al (1997): Outbreak of canine distemper in vaccinated dogs in Finland. Vet Rec, 141, 380-383.

16. Elia G, Camero M, Losurdo M, et al (2015): Virological and serological findings in dogs with naturally occurring distemper. J Virol Methods, 213, 127-130.

17. Elia G, Decaro N, Martella V, et al (2006): Detection of canine distemper virus in dogs by real-time RT-PCR. J Virol Methods, 136, 171-176.

18. Esin E (2013): Köpeklerde Canine Distemper Virus enfeksiyonunun araştırılması. Doktora Tezi. Selçuk Üniversitesi Sağlık Bilimleri Enstitüsü, Konya.

19. Fong TT, Lipp EK (2005): Enteric viruses of humans and animals in aquatic environments: health risks, detection, and potential water quality assessment tools. Microbiol Mol Biol Rev, 69, 357-371.

20. Gray LK, Crawford PC, Levy JK, et al (2012): Comparison of two assays for detection of antibodies against canine parvovirus and canine distemper virus in dogs admitted to a Florida animal shelter. J Am Vet Med Assoc, 240, 1084-1087.

21. Greene CE (2013): Infectious diseases of the dog and cat. Elsevier Health Sciences, London.

22. Gustavsson L, Westin J, Andersson LM, et al (2011): Rectal swabs can be used for diagnosis of viral gastroenteritis with a multiple real-time PCR assay. J Clin Virol, 51, 279-282.

23. Headley SA, Sukura A (2009): Naturally occurring systemic canine distemper virus infection in a pup. Braz $\mathbf{J}$ Vet Pathol, 2, 95-101.

24. Jóžwik A, Frymus T (2002): Natural distemper in vaccinated and unvaccinated dogs in Warsaw. J Vet Med, 49, 413-414.

25. Kapil S, Neel T (2015): Canine distemper virus antigen detection in external epithelia of recently vaccinated, sick dogs by fluorescence microscopy is a valuable prognostic indicator. J Clin Microbiol, 53, 687-691.

26. Keawcharoen J, Theamboonlers A, Jantaradsamee P, et al (2005): Nucleotide sequence analysis of nucleocapsid protein gene of canine distemper virus isolates in Thailand. Vet Microbiol, 105, 137-142.

27. Lan N, Yamaguchi R, Inomata A, et al (2006): Comparative analyses of canine distemper viral isolates from clinical cases of canine distemper in vaccinated dogs. Vet Microbiol, 115, 32-42.

28. Lednicky JA, Meehan TP, Kinsel MJ, et al (2004): Effective primary isolation of wild-type Canine distemper virus in MDCK, MV1 Lu and Vero cells without nucleotide sequence changes within the entire haemagglutinin protein gene and in subgenomic sections of the fusion and phospho protein genes. J Virol Methods, 118, 147-157.

29. Lorusso A, Savini G (2014): Old diseases for new nightmares: distemper strikes back in Italy. Vet Ital, 50, 151-154. 
30. MacLachlan NJ, Dubovi EJ (2016): Paramyxoviridae and pneumoviridae. In: MacLachlan NJ, Dubovi EJ, editors. Fenner's veterinary virology. $5^{\text {th }}$ ed. London, UK: Academic press, 327-56.

31. Madeley CR, Peiris JSM (2002): Methods in virus diagnosis: immunofluorescence revisited. J Clin Virol, 25, 121-134.

32. Martella V, Cirone, F, Elia G, et al (2006): Heterogeneity within the hemagglutinin genes of canine distemper virus $(C D V)$ strains detected in Italy. Vet Microbiol, 116, 301309.

33. Martinez-Gutierrez M, Ruiz-Saenz J (2016): Diversity of susceptible hosts in canine distemper virus infection: a systematic review and data synthesis. BMC Vet Res, 12, 78.

34. Nuanualsuwan S, Cliver DO (2002): Pretreatment to avoid positive RT-PCR results with inactivated viruses. J Virol Methods, 104, 217-225.

35. Origgi F, Plattet P, Sattler U, et al (2012): Emergence of canine distemper virus strains with modified molecular signature and enhanced neuronal tropism leading to high mortality in wild carnivores. Vet Pathol, 49, 913-929.

36. Özkul A, Sancak AA, Güngör E, et al (2004): Determination and phylogenetic analysis of canine distemper virus in dogs with nervous symptoms in Turkey. Acta Vet Hung, 52, 125-132.

37. Pawar RM, Raj GD, Gopinath VP, et al (2011): Isolation and molecular characterization of canine distemper virus from India. Trop Anim Health Prod, 43, 1617-1622.

38. Richards GP (1999): Limitations of molecular biological techniques for assessing the virological safety of foods. $\mathbf{J}$ Food Prot, 62, 691-697.

39. Roelke-Parker ME, Munson L, Packer C, et al (1996): A canine distemper virus epidemic in Serengeti lions (Panthera leo). Nature, 37, 441-445.

40. Sahna K, Gencay A, Atalay O (2008): Viral aetiology of diarrhoea in puppies from a same shelter in Turkey: presence of mixed infections. Rev Med Vet, 159, 345-346.

41. Saito T, Alfieri A, Wosiacki S, et al (2006): Detection of canine distemper virus by reverse transcriptase-polymerase chain reaction in the urine of dogs with clinical signs of distemper encephalitis. Res Vet Sci, 80, 116-119.

42. Saltık HS, Kale M (2020): Evaluation of infection with $N$ protein-specific Immunoglobulin $M$ and $G$ in naturally occurring distemper in dogs. Vet Med-Czech, 65, 168-173.

43. Schobesberger M, Summerfield A, Doherr MG, et al (2005): Canine distemper virus-induced depletion of uninfected lymphocytes is associated with apoptosis. Vet Immunol Immunopathol, 104, 33-44.

44. Seki F, Ono N, Yamaguchi R (2003): Efficient isolation of wild strains of canine distemper virus in Vero cells expressing canine SLAM (CD150) and their adaptability to marmoset B95a cells. J Virol, 77, 9943-9950.

45. Shin YJ, Cho KO, Cho HS, et al (2004): Comparison of one-step RT-PCR and a nested PCR for the detection of canine distemper virus in clinical samples. Aust Vet J, 82, 83-86.

46. Swati, Deka D, Uppal SK, et al (2015): Isolation and phylogenetic characterization of Canine distemper virus from India. VirusDisease, 26, 133-140.

47. Tan B, Wen YJ, Wang FX, et al (2011): Pathogenesis and phylogenetic analyses of canine distemper virus strain ZJ7 isolate from domestic dogs in China. Virol J, $8,1$.

48. Temilade BE, Solomon OOO, Omotayo OE, et al (2015): Seropositivity of Canine Distemper Virus (CDV) in Dogs Presenting at Abeokuta, Nigeria. Public Health Research, 5, 109-119.

49. Wyllie SE, Kelman M, Ward MP (2016): Epidemiology and clinical presentation of canine distemper disease in dogs and ferrets in Australia, 2006-2014. Aust Vet J, 94, 215-222.

\section{Publisher's Note}

All claims expressed in this article are solely those of the authors and do not necessarily represent those of their affiliated organizations, or those of the publisher, the editors and the reviewers. Any product that may be evaluated in this article, or claim that may be made by its manufacturer, is not guaranteed or endorsed by the publisher. 